\title{
Holocene Climate Change in the Asian Region
}

\section{LIMPACS Workshop - Chandigarh, India, 5-8 March 2009}

Peter Gell ${ }^{1}$, B. Kotlia ${ }^{2}$ and Q. Wen ${ }^{3}$

${ }^{1}$ University of Ballarat, Australia; p.gell@ballarat.edu.au; ${ }^{2}$ Kumaun University, Nainital, India ${ }^{3}$ Chinese Academy of Geological Sciences, Beijing, China.

The $3^{\text {rd }}$ meeting under the "Salinity, Climate Change and Salinisation" working group of LIMPACS (Human impacts on lake ecosystems), a PAGES Focus 4 Working Group, was held in Chandigarh from 5-8 March 2009. This meeting followed those from October 2004 in Mildura, Australia and April 2007 in Nanjing, China. The meeting was jointly organized by Kumaun and Panjab Universities and was supported by PAGES, the Indian Council of Scientific and Industrial Research, and the Indian Oil and Natural Gas Commission. Over 70 participants attended from Australia, USA, UK, France, Germany, Russia, Bulgaria, Poland and China, as well as a strong contingent of Indian scientists and early career researchers.

This meeting focused on key extreme climate events (particularly decadal scale climatic changes) through the Holocene, across the Indian subcontinent and China including Tibet, with other contributions from studies in Mongolia, Lebanon, Siberia, Bulgaria, Botswana, California and Australia. Clear evidence was provided for the widespread impact of the Younger Dryas, 8.2 and 4.2 ka events, Medieval Warm Period and Little Ice Ages across the region, which, while evident, produce differential outcomes in terms of available moisture (Fig. 1). Another key theme addressed was the response of people to climatic fluctuations as expressed by societal collapse, migrations or changing technologies and economies.

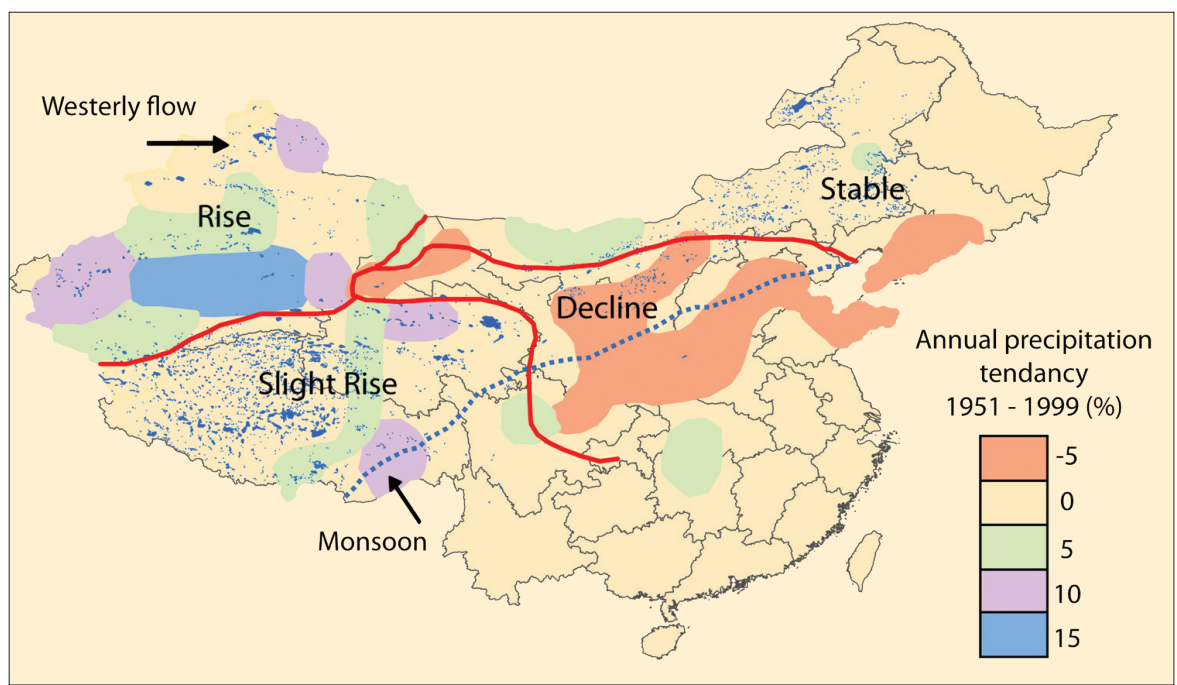

Figure 1: Water level changes across west China since the 1970s, based on topographic mapping and remotely sensed imagery. The levels of most lakes in western China fell through to the mid 1990s but have risen since due to increased rainfall.

Following the presentations, discussions were held that identified research priorities for the region. These comprised (1) stronger cooperation between climatologists and modelers, (2) improved dating techniques with better calibration, (3) an intention to generate better estimations of actual climatic parameters (temperature and humidity) through proxies and (4) a plan to develop a regional database of records of climate and water budgets for Asia, especially across the Indian subcontinent. It was also felt that a better understanding of the connection between climate change processes and civilization and culture would aid the prediction of climate-driven catastrophes and mitigate their impact in the future.
The proposal to develop a regional network, first tabled at the Nanjing meeting, was developed with a proposal to launch the "Across the Third Pole" (ATP) research network, to encourage the development of regional syntheses to explore the impact of recent climate change and human impact on lake ecosystems across the Himalayan slopes and Tibetan Plateau. It was agreed to meet again in Bulgaria in September/October 2011 to collate recent records of human impact, and to advance the aims of the ATP network by identifying sites and supporting research in key sites across the region.

\section{East African Quaternary: Lessons from the past for the future}

\section{The $2^{\text {nd }}$ Eastern African Quaternary Research Association (EAQUA) Workshop - Addis Ababa, Ethiopia, 21-24 May 2009}

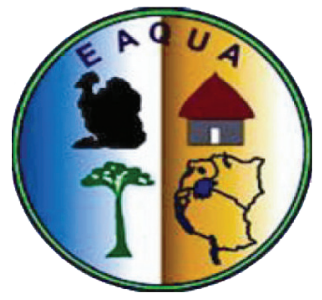

Asfawossen Asrat and Mohammed Umer

Department of Earth Sciences, Addis Ababa University, Ethiopia; asrata@geol.aau.edu.et

The $2^{\text {nd }}$ East African Quaternary Research Association (EAQUA) workshop was held in Addis Ababa, Ethiopia from 21-22 May 2009, followed by a post-workshop field trip to the Main Ethiopian Rift on 23-24 May. The workshop was organized by the Department of Earth Sciences, Addis Ababa University in collaboration with EAQUA; and was sponsored by PAGES, START, INQUA, the Paleo-Anthropology Scientific Trust, British Institute in Eastern Africa, the Revealing Hominid Origins Initiative, and local institutions (Addis Ababa University, Authority for Research and Conservation of Cultural Heritages, and Ministry of Science and Technology). The Workshop was officially opened by the State Minister of the Ministry of Culture and Tourism of Ethiopia.

The primary objectives of the workshop were to strengthen and enhance active communication on Quaternary research issues in the Eastern African region, and to serve as a forum for initiating new 